\title{
The Impact of the Coronavirus Pandemic (COVID-19) Consequences on Phonetic Aspect of a Foreign Language Teaching in Specialized Linguistic Specialties at Universities
}

\author{
Popova M.V.* Rozhdestvenskaya E.I.
}

\author{
The Maurice Thorez Institute of Foreign Languages, Moscow State Linguistic University, Moscow 119034, Russia \\ *Corresponding author. Email:neunerin@gmail.com
}

\begin{abstract}
This article presents an overview of the psychological and pedagogical consequences of switching to a remote learning format for linguistic specialties at the specialized university due to the coronavirus pandemic (COVID19). The article presents the sociological survey results conducted among the linguistic specialities students of of MSLU (Moscow State Linguistic University) in August 2020 on the pandemic consequences impact nature on the pedagogical process in general and on special issues of teaching language arts, in particular the phonetic aspect. The study results indicate that the difficulties experienced by students are primarily associated with insufficient technical equipment. Moreover, there are problems with concentration, self-discipline, motivation, as well as a lack of interpersonal communication. Within the phonetic aspect framework, the perceptive-auditive and visual perception peculiarities in the remote learning format conditions and mask requirements in face-toface learning format are studied. The conclusions on the need to combine learning formats are drawn. Combining them is necessary for increasing the educational process effectiveness and reducing the students' psychological discomfort and the risk of being infected.
\end{abstract}

Keywords: remote learning, blended learning, phonetics, Web 2.0 tools, the coronavirus pandemic (Covid-

19) psychological and pedagogical consequences

\section{INTRODUCTION}

According to UNESCO (April 20, 2020), 91.3\% of the total number of students worldwide felt the effects of the pandemic, which led to the educational institutions closure, students were switched to remote learning. The most serious problems of remote learning in the Russian Federation are the technical difficulties caused by the financial inability of many citizens to provide a sufficient level of technical equipment at home, according to the research. The scientists also say that both students and lecturers are not ready for this format from the psychological point of view. In their turn, psychological problems associated with children's unwillingness to organize themselves, lack of "live" communication, and problems with concentration and understanding of material are no less important in these conditions [1].

It should be noted that the nature of the difficulties faced by lecturers and students to a large extent depends on the education level and specialization. The study program in linguistic specialties is characterized by a large number of disciplines based on oral communication. In particular, most practical and theoretical classes on language aspects are conducted in foreign languages. At first sight, it may seem that the remote learning format does not have a significant impact on the learning process, since students do not need to work in laboratories or present the results of their projects that require special equipment and conditions, as in cases, for example, with doctors, chemists or architects. However, this statement can be true only if all the participants of remote learning have adequate technical equipment.

\section{METHODOLOGY}

To identify the features of the coronavirus pandemic (COVID-19) impact on the educational process within the framework of learning in linguistic areas on the basis of the MSLU, an online survey was conducted on the Google Forms platform. 210 people ( 30 men and 180 women) aged 18 to 41 took part in the survey. The survey was conducted among the students of German, French and English and the translation faculties of full-time and part-time education. Among the respondents, 190 are currently studying for a bachelor's degree, 18 -are studying for a master's degree, and 2- are studying for a $\mathrm{PhD}$. The faculties choice is determined by the specifics of training, which involves a large number of purely linguistic disciplines conducted in foreign languages, as well as the presence of practical classes on the phonetic aspect. 
In general, the switch to a remote learning format was accepted ambiguously by students: $21 \%$ rated the switch "very positive", $38.6 \%$ - "rather positive", $23.8 \%$-"rather negative", $16.7 \%$-"very negative". At the same time, $41.9 \%$ of respondents believe that this has led to a decrease in the educational services quality (Figure 1).

\title{
How has the level of quality of educational services provided at MSLU changed in connection with the transition to distance learning due to the coronavirus pandemic (Covid-2019)? 210 responses
}

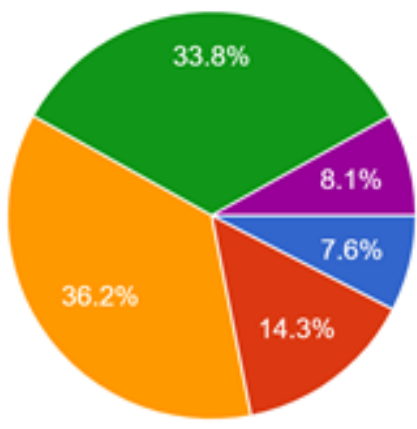

\author{
will improve significantly \\ would rather improve \\ did not change \\ rather worsened \\ worsened significantly
}

Figure 1. The figure for evaluating the educational services quality provided in MSLU as a result of the switch to remote learning from the students' point of view

The majority of respondents indicated a PC or laptop $(87.9 \%)$ as the technical means, as well as $78.3 \%$ indicated a smartphone as the technical means used in the training process. 152 respondents $(72.4 \%)$ used $\mathrm{Wi}-\mathrm{Fi}, 102$ respondents $(48.6 \%)$ used mobile Internet (3G, 4G, LTE). At the same time, more than $80 \%$ of students rated their computer skills as "quite high", $16.3 \%$ believe that they have insufficient computer skills, and three respondents $(1.4 \%)$ rated their skills "very low". Teaching staff digital competence assessments of from the position of students are also quite high: $70.7 \%$ of respondents noted a "very high" and "rather high" level of computer skills development ( $7.3 \%$ and $63.4 \%$, respectively). $25.4 \%$ of students gave the technical training of lecturers a low rating, and $3.9 \%$ of respondents gave -a very low rating.

The level of satisfaction by interaction with lecturers during remote learning compared to face-to-face learning decreased insignificantly (by $11.6 \%$ ), but in general remained quite high $(82.8 \%)$. But the switch to the remote learning had a significant negative impact on the communication between students: the number of students completely satisfied with communication decreased from more than $70 \%$ to $43.3 \%$. At the same time, the total percentage of students, unsatisfied with communication, increased from $7.2 \%$ to $30.9 \%$, including $11.9 \%$ who were "completely unsatisfied".

There is a positive trend in the ICT (information and communication technology) use. The results show a significant increase in the ICT use in teaching, compared to the period before the switch to the remote format. The overall percentage of students who never used LMS or rarely used it dropped from $90 \%$ to $53.8 \%$. In turn, the percentage of regular users of Moodle increased from $1 \%$ to $21 \%$.

Web 2.0 tools, such as Kahoot, Quizizz, Google Forms and others have been used much more frequently in the learning process. The percentage of respondents who never used them before switching to the remote format decreased from $42.4 \%$ to $20 \%$, while the indicators for regular and frequent use increased by $16.6 \%$ and $11.4 \%$, respectively. Also, online broadcasts (streams) were actively used in the learning process. The regular and frequent use of streams increased from $0.5 \%$ to $25.2 \%$ and $17.1 \%$, respectively. It should be noted that before the introduction of restrictive measures due to the pandemic, $70 \%$ of respondents had no experience with online broadcasts, but during the remote learning process it decreased by almost three times - to $21 \%$. The regular use of mobile apps increased from $8.6 \%$ to $37.1 \%$. The overall percentage of students who have never used mobile apps or rarely used them dropped from $43 \%$ to $18.1 \%$. According to the survey, podcasts, blogs, and videos were used before switching to remote mode. However, the frequency of their use was quite low: $21.4 \%$ have never resorted to the use of audio-visual means during the lesson, $24.8 \%$ did it rarely, and $32.4 \%$-did it periodically. In this case, the figures have not changed significantly.

Among the most serious problems associated with learning, before switching to the remote format, the majority of respondents noted the combining study with work or parttime work (37.6\%) and a long time to prepare for classes 
(62.9\%). The most common problems during the remote format were limited social life $(62.4 \%)$, problems with concentration $(51.9 \%)$, long time to prepare for classes $(48.1 \%)$, problems with self-discipline $(45.2 \%)$, lack of motivation (45\%) and household responsibilities (39\%). (Figure 2)

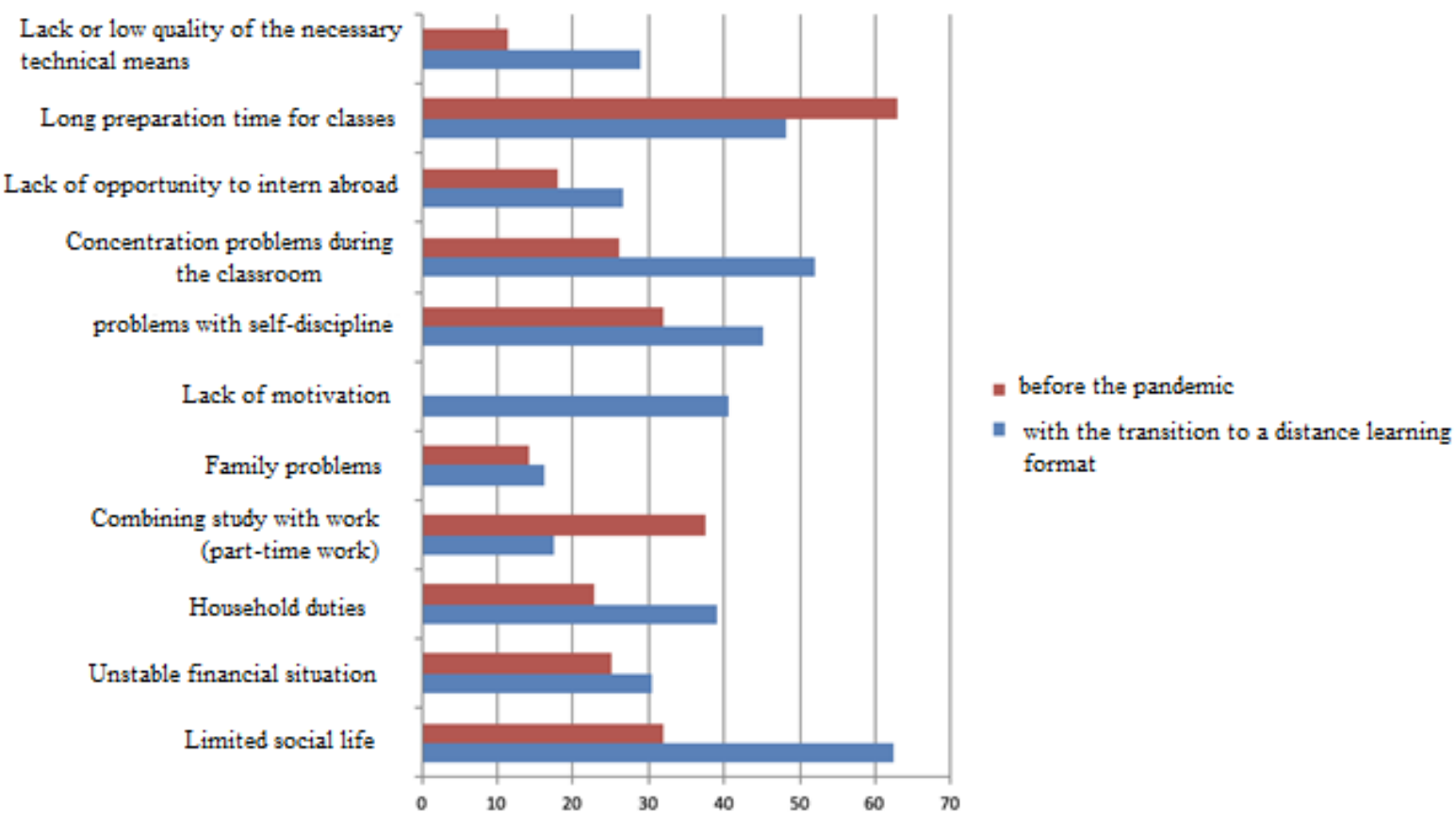

Figure 2 The cross plot of survey results on learning-related issues before and during the coronavirus pandemic (COVID-19)

On the cross plot we can see that in most cases the transition to remote learning has worsened the problems. This is seen especially in relation to motivation. Most respondents did not have any problems with motivation before the pandemic, but $41 \%$ of respondents encountered with this problem during remote learning. The number of people experiencing problems with concentration during the educational process has almost doubled (from $26 \%$ to $52 \%$ ). The number of respondents experiencing problems due to limited social life has increased from $32 \%$ to $62 \%$. Among these problems a positive trend is observed only in two cases. One case is reducing the time to prepare for lessons. The decrease in the number is clearly seen, because this indicator has dropped from $63 \%$ to $48 \%$. The other case is combining work with study, where the number of respondents has decreased from $38 \%$ to $18 \%$.

As for the phonetic aspect, the survey participants rated the effectiveness of organizing classes before the pandemic. $51.4 \%$ of respondents considered them "very effective", $37.1 \%$-"rather effective". With the switch to remote learning, the number of students who chose these items equals to $20.5 \%$ and $49.5 \%$, respectively. The percentage of respondents who are less satisfied with the effectiveness of classes in general has increased from $11.4 \%$ to $30 \%$. The level of students' personal comfort in phonetics classes during remote learning has also changed. The number of respondents who feel uncomfortable has almost doubled from $18.6 \%$ to $33.8 \%$. The visual component in phonetic classes is important for the majority of respondents: $44.3 \%$ considered it "very important", and 33.8\% -considered it "rather important". Observing the lecturer's articulatory organs patterns and movements plays an equally important role for students. $51 \%$ considered this opportunity "very important", $39 \%$-considered it "rather important". At the same time, the majority of students $(86.2 \%)$ consider it necessary that a lecturer should be present at the phonetic classes. The absolute majority of respondents agreed that the acoustic component is very important. $88.1 \%$ of respondents considered it very important, $11.4 \%$-considered it rather important. Also, more than a half of the respondents $(50.5 \%)$ believe that the forced mask wearing significantly worsens the understanding of oral speech in face-to-face communication, and $41 \%$ of students believe that it "rather worsens". We asked about the best way of conducting an introductory-phonetic course in the first term remotely by video conferencing compared to faceto-face format of learning in the mask mode. The opinions of the respondents have divided: $23,8 \%$ said that the remote format is "significantly more effective", $19 \%$-considered it "somewhat more effective", with $15.2 \%$ considered both variants "equally effective", $25.7 \%$ are sure that the remote mode with the video communication is less effective and $16.2 \%$ considered it not effective at all.

\section{DISCUSSION}


The switch to the remote learning caused mixed reactions among students. We believe that this happened due to the difficulties caused by the technical equipment necessary for conducting remote classes. Taking into account the restricting movement decree being effective in Moscow from March 30, 2020 to June 19, 2020 and the self-isolation regime introduction, some students chose to return home to the regions or go to the country, where technical capabilities, especially the quality and speed of Internet connection, are inferior to the Moscow region ones. In addition, according to the survey results, a large percentage of students used mobile devices (smartphones) to participate in video conferences. The software functionality of mobile devices in video conferences apps is limited compared to the PC video conferences apps. In this connection, it should be noted that the most popular video conferencing programs are quite traffic-consuming. For example, in a video conference with three or more participants on average, Zoom requires about $810 \mathrm{MB}$ per hour, Discord- requires about $700 \mathrm{MB}$ per hour and Skype - in a group video call (more than 7 participants) -requires $3.91 \mathrm{~GB}$. While conducting classes, the screen display function was often used, which increased the amount of traffic consumed. The information described above indicates the need for tariffs that involve a significant number of enabled transmitted information volumes or unlimited Internet use, and this option increases the tariff cost. According to our calculations, based on the standard schedule for language specialties involving three lessons a day five days a week, on average, about $18 \mathrm{~GB}$ of traffic is needed when using Zoom. The average user consumes about 12-15 GB of traffic per month [2]. Thus, traffic increases by 2 times on average. Also, the proximity of cell towers to localities plays an important role. It affects the quality of the Internet connection significantly. It should also be noted that the load on the Internet while using the Internet connection by several people at once increases. And this negatively affects the speed and quality of the Internet connection. In general, we can make a conclusion that for a full switch to the remote learning format, it is necessary to have at least one device that meets the requirements of the above-mentioned video conferencing platforms and a stable high-speed Internet connection without traffic restrictions or with a traffic volume of at least 35 GB per month for one student.

In our opinion, the marked tendency towards a decrease in the level of satisfaction with communication between students can be explained by the interpersonal contacts restriction. The comparative analysis of the level of satisfaction with communication between students and lecturers shows it. This idea is also confirmed by the respondents' answers to the questions about problems related to education. Students say that one of the most important problems is the restriction of social life due to the introduction of a self-isolation regime. For the majority of the population, self-isolation is already a cause of stress: the daily routine and the established format of work and training processes are disrupted, emotional tension increases and a depressing state of anxiety arises due to information overload and uncertainty. In addition, for students, a place is not only an educational institution where they receive professional knowledge but also an institution for socialization. Thanks to this institution, they become a part of various extracurricular associations, such as sports and art sections. And within these institutions, informal communication usually takes place [3]. With the switch to the remote format, students lost the opportunity for interpersonal interaction, which, according to the results of the survey, is of great importance for them. Alongside the limited social life, respondents also noted the aggravation of problems with motivation, self-discipline and concentration during the learning process. We believe that general emotional tension, anxiety caused by uncertainty in all spheres of life, lack or insufficiency of the necessary technical equipment, together with psychological problems, can have a serious impact on the effectiveness of training, students' progress, as well as their involvement in the educational process. According to some researchers, it is impossible to maintain the current level of education quality with the forced emergency switch to the remote format. The quality of education will suffer because lecturers communicate with students less. The visual component is absent, so the emotional and paraverbal components of communication are lost. In other words, students do not have the possibility of some "emotional discharge" that was expressed in spontaneous comments, discussions among themselves, switching attention, changing activities, etc. during face-to-face learning [4]

The specifics of teaching phonetics in face-to-face and remote formats are of particular interest to us. It is so because the presence of practical classes and many hours of face-to-face communication with a phonetics professor within the introductory phonetic course is a distinctive feature of teaching a foreign language in linguistic specialities. This aspect is characterized by increased auditory channel activation. It also requires direct eye contact, especially at the initial stages of study. Teaching pronunciation assumes the auditory-pronunciation skills development, which, among other things, implies the phonemic and intonation hearing development, the respiratory organs and articulation apparatus development for their adaptation to the pronunciation norm peculiarities of the language studied [5]. Learning at the initial stages is based directly on the imitative method. Using this method students imitate the patterns and movements of the lecturer's articulatory organs. They receive information through the visual channel, as well as pronouncing norms at the segmental and suprasegmental levels, copying the samples obtained through the auditory channel demonstrated by the lecturer or speaker on audio recordings. Accordingly, there is a need to study the impact of remote foreign language learning in general and the phonetic aspect in particular. Despite the appropriate level of lecturers' training that allowed to switch to the remote format quickly, there is an increase in student dissatisfaction with the effectiveness of phonetic classes and students' personal comfort. We assume that this happens primarily due to the technical side of the issue since, during face-to-face learning, a lecturer can give a task for individual testing of certain techniques and observe students, comment on the difficulties that students 
face. Face-to-face learning assumes that a lecturer can visually and auditorily monitor the group, identify students who need to be corrected. In a video conference environment, not everyone has a visual component. The general sound flow characterized by mutual overlap can lead to significant distortion, which causes difficulties in perception and speaker's identification. Thus, to reveal difficulties, a lecturer needs to listen to each student separately, which reduces the time to practice on the planned material. In addition, group work is completely excluded. It is also difficult to work in pairs or mini-groups, since the function of creating additional channels within the current conference requires payment on some platforms (for example, in Zoom). A lecturer can not control all channels at the same time, since it requires a connection to each of them. Probably, for this reason, more than $85 \%$ of respondents note the need for the lecturer personal presence in the classroom.

The absolute majority of students note the importance of the acoustic aspect in phonetics classes and difficulties in communication due to wearing a mask. However, the respondents' reactions regarding the prospect of replacing face-to-face classes wearing a mask with a video conference format are ambiguous. Thus, the switch to a remote learning format is not an effective alternative to face-to-face learning within phonetics learning, according to students. In this regard, one question arises: how to make the educational process productive without the loss of quality, taking into account possible problems with technical equipment, motivation, concentration and students' self-organization, as well as the specifics of training in the discipline and students' personal comfort?

Currently, the term "blended learning" is very popular in the field of foreign language teaching (in particular, within the framework of SLA), which, in turn, has different interpretations depending on the approach, country and culture [6]. P. Sharma with colleagues emphasize that this term has undergone significant changes in interpretation and has been repeatedly reinterpreted over almost 20 years of existence. Among the most common models of blended learning are: face-to-face + online training, a combination of technologies, a combination of real world plus virtual world [7]. The most interesting method, in our opinion, is the first one. It suggests combining the traditional format with online sessions involving the use of various remote tools, such as LMS, Web 2.0, etc. One of the main advantages of implementing this approach is "flexibility". Lecturers can choose various tools that will be most appropriate for certain skill formation or topic consolidation. In addition, it is necessary to emphasize adaptivity, which allows students to build the learning process most effectively in accordance with their opportunities and needs. However, this approach is also criticized due to the fact that students often prefer one of the formats (face-to-face or remote). Therefore, despite the "compromise" of this approach, in the end, many students may remain dissatisfied.

Taking into account the specifics of the phonetic aspect, in some forms of work, in particular, when explaining new material related to the articulatory organs work and structures, the most important is the visual component. But the visual component implementation is difficult in the conditions of mandatory mask-wearing. In this regard, we assume that the introduction of new material should be conducted with the help of video conferences on such platforms as Zoom, Discord and the like. In turn, when students train individual elements of the segmental and suprasegmental levels, the perceptual-auditory aspect plays the most important role. So the maximum effect can be achieved during face-to-face learning even in the conditions of mandatory mask-wearing. Video materials can serve as auxiliary tools for working out sound extraction. They can be formed on the basis of online conferences video recordings. Thus, if there are difficulties associated with the incorrect movement of the student's articulatory organs, a lecturer can demonstrate the normative variant with the help of a video, so the lecturer can keep wearing a mask during the lesson.

According to our survey, respondents generally note that both themselves and MSLU lecturers and professors have a high level of digital competence. This is also evidenced by the answers of the respondents regarding the use of Web 2.0 tools in the foreign language classes. It should be stressed that there is a significant increase in the use of various programs, platforms and applications that were rarely used or not used at all before switching to the remote format. According to research, the use of Web 2.0 tools, especially with the game elements, significantly increases the students' motivation [8], [9], [10]. Some of the most powerful tools are applications such as Quizizz, Kahoot, Quizlet or Socrative, which can be used as control elements and help improve students' self-organization skills and selfdiscipline. Tasks that are formed on the basis of these programs are online quizzes with various formats of questions. These programmes can be used both in the classroom while students work in mini-groups (game element), or individually as a homework assignment with a fixed deadline. We believe that the main advantage of these programs is not only the game component that helps students escape the generally accepted perception of the learning process as "boring". Time limit set and regulated by the teacher during the creation of the quiz for each question increases the level of concentration. And the possibility to take the control element outside the classroom without fear of violating the ethical standards of the students' performance due to the limited time allows the lecturer to spend more time on practical working out of the material, which is a key factor in setting the normative pronunciation in a foreign language.

Blended learning also partially solves the issue of social restrictions, since during face-to-face learning students have the opportunity to communicate among themselves and socialize in their usual conditions. It is also proposed to use online quests and excursions designed on the basis of platforms such as Questie, izitravel, etc. as control tools. The possibility of individual quests completing reduces the students' direct interaction time with each other and allows to expand the boundaries of the usual work on the one hand, and considerably increases physical activity levels decreased significantly during isolation on the other hand. 
In addition, the designing of an online quest involves the inclusion of not only tasks in the discipline, but also tasks for logic, abstract thinking and creativity, which contributes to the development of the 21 st century competencies that are necessary today.

\section{CONCLUSION}

Thus, the switch to a blended learning is, in our opinion, a compromise solution that will allow combining forced distance learning and the usual face-to-face learning modes. Based on the specifics of linguistic specialities, in particular, the features of teaching the phonetic aspect, it can be concluded that the face-to-face learning format can solve problems related to the technical organization of the educational process and reduce the consumed Internet traffic, eliminate problems with the quality of the connection. The face-to-face learning format also follows the usual format of personal interaction with the teacher whereas informal interpersonal contact between students and frequent change of activities are also possible. During face-to-face learning, perceptual-auditory exercises are also more effective. In turn, the remote format provides a clear and safe demonstration of movements and patterns of articulatory organs, increases students' motivation by introducing gamification elements into the learning process, and the use of certain Web 2.0 tools increases concentration and develops self-organization and time management skills. We think that blended learning will also reduce the sickness rate as the rotation of workstations and language booths will be less frequent. This will provide the essential time to carry out the necessary disinfection measures in accordance with WHO regulations and recommendations of the Federal service for supervision of consumer rights protection and human welfare.

\section{REFERENCES}

[1] O. Bashlakova, On Some Issues of Distant Learning in Russia in the Period of the Pandemic, Legal education and science, 7, 2020, pp. 15-19. DOI: 10.18572/1813-1190-2020-7-15-19

[2] A.I. Itsikson, Territorial'naya organizatsiya informatsionnogo trafika $v$ regionakh Rossii, in: Vestnik Yuzhno-Ural'skogo gosudarstvennogo universiteta, Ekonomika i menedzhment, 14(1), 2020, pp. 44-52. DOI: 10.14529/em200105

[3] R.R. Khizbullina, Obucheniye v vuze kak protsess sotsializatsii: metodologicheskiy aspekt, Molodoy uchenyy, 5 (64), 2014. pp. 445-447.

[4] Ye.V. Oleynik, D.A. Mutalova, T.A. Bezenkova, A.V. Manannikova, Izucheniye problemy adaptatsii studentov vuza v usloviyakh samoizolyatsii k on-line obucheniyu s primeneniyem distantsionnykh obrazovatel'nykh tekhnologiy, Sovremennoye pedagogicheskoye obrazovaniye, 5, 2020, pp. 69-72.

[5] E.G. Azimov, A.N. Shchukin, Novyı̌ slovar' metodicheskikh terminov i ponyatiı̌ (teoriya i praktika obucheniya yazykam), M.: Izdatel'stvo IKAR, 2009, $448 \mathrm{~s}$.

[6] G. Motteram, P. Sharma, Blending learning in a web 2.0 world, in: Australian Journal of Emerging Technologies and Society. 7 (2), 2009, pp. 83 96. DOI: 10.1016/j.sbspro.2010.03.417

[7] M. Oliver, K. Trigwell, Can "Blended Learning" Be Redeemed? in: E-Learning, 2 (1), 2005, pp. 17-26. DOI:10.2304/elea.2005.2.1.17

[8] Ye.V. Karmanova, A.N. Starkov, V.V. Vikulina, Vozmozhnosti primeneniya tekhnologii geymifikatsii pri realizatsii elektronnogo obucheniya v vuze, in: Perspektivy nauki i obrazovaniya, 40 (4), 2019, pp. 462-472. DOI: $10.32744 /$ pse.2019.4.35

[9] Ye. O. Tsyplakova, Geymifikatsiya motivatsionnaya praktika ili mekhanizm total'nogo kontrolya nad trudovym protsessom? In: Ekonomicheskaya sotsiologiya, 17 (3), 2016, pp. 82109.

[10] S.V. Titova, K.V. Chikrizova, Geymifikatsiya v obuchenii inostrannym yazykam: psikhologodidakticheskiy i metodicheskiy potentsial, in Pedagogika i psikhologiya obrazovaniya, №1, 2019, pp. 135-152. 